\title{
Prognosis for infants born at 23 to 28 weeks' gestation
}

\author{
V Y H YU, H L LOKE, B BAJUK, W SZYMONOWICZ, A A ORGILL, J ASTBURY
}

\begin{abstract}
The survival and neurodevelopmental outcome of 356 extremely preterm infants born at 23 to 28 weeks' gestation were reported by week of gestation. Their corrected 1 year survival improved from $7 \%$ at 23 weeks to $75 \%$ at 28 weeks. The overall incidence of impairment was $19 \%$ and of major disability $12 \%$. Boys had a significantly lower normal survival than girls. Multiple births had a significantly lower survival and higher incidence of impairment than singleton births. Predictions of outcome were made before delivery, after resuscitation, and at 1 week to aid the development of guidelines on when perinatal intensive care is justified, whether obstetric intervention for fetal reasons is warranted, and what initial and ongoing prognoses to give to parents.

Intensive care for progressively smaller and more immature infants, many of whom were previously considered non-viable, needs to be carefully monitored by every perinatal centre.
\end{abstract}

\section{Introduction}

Advances in perinatal care have been associated with improved survival in extremely preterm infants born at 23 to 28 weeks' gestation. The provision of intensive care for those infants previously considered to be non-viable has prompted many philosophical, ethical, legal, and economic questions. Obstetric decision making in the management of such extremely preterm labour and delivery has become increasingly difficult, as increasing numbers of such infants are surviving intact. ${ }^{1-3}$ Gestation, not birth weight, however, is the parameter that must be used by the obstetrician as a guide to making critical decisions about the care of the mother and fetus. Gestation is a better predictor of outcome because of the inherent inaccuracies in clinically or sonographically estimating fetal weight. ${ }^{4}$ To provide more information on the prognosis of extremely preterm infants we report on their survival and neurodevelopmental outcome by week of gestation in this study.

\section{Patients and methods}

All inborn consecutive livebirths of 23 to 28 weeks' gestation delivered at Queen Victoria Medical Centre, Melbourne, Australia, from 1 January 1977 to 31 December 1984 were studied. This perinatal centre is one of three that are reponsible for providing a regional perinatal service to the state of Victoria, where antenatal identification and in utero transfer of high risk pregnancies are strongly encouraged. ${ }^{5}$ A livebirth was defined as one who breathed or showed any evidence of life such as beating of the heart or definite movement of voluntary muscles. ${ }^{6}$ The obstetricians' prenatal estimations of gestational age based on menstrual data or an ultrasonic examination of the gestational sac in the first trimester, or both, were used exclusively in the analysis. Postnatal assessment of maturity was not relied on in this study because of its known inaccuracies in extreme prematurity.

All extremely preterm survivors were enrolled in a long term follow up

Department of Paediatrics, Monash University, Melbourne, Australia

V Y H YU, FRACP, FRCP, director of neonatal intensive care and clinical associate professor of paediatrics

H L LOKE, MMED(PAED), neonatal fellow

B BAJUK, SRN, SCM, research nurse

W SZYMONOWICZ, FRCPC, staff neonatologist

A A ORGILL, FRACP, developmental paediatrician

J ASTBURY, MED, PHD, clinical psychologist

Correspondence to: Professor V Yu, Department of Paediatrics, Queen Victoria Medical Centre, Melbourne, Victoria 3000, Australia. programme at the centre.$^{8} 9$ Results of the assessment at 2 years of age, corrected for prematurity, were presented except for those survivors born in 1984 , for whom only data at the corrected age of 1 year were available. At the growth and development clinic these children were clinically, neuro- $-\overrightarrow{0}$ logically, and psychologically assessed by a multidisciplinary team. The Bayley scales of infant development were used. Impairment was defined as $\overline{\bar{\omega}}$ cerebral palsy of any type or severity, developmental delay diagnosed by a $\vec{\sigma}$ mental developmental index of more than two SD below the mean, $\mathbb{Q}$ blindness, or sensorineural deafness. ${ }^{10}$ Major disability, which is a measure $\cong$ of severe loss of function, was defined as impairment as mentioned above $\rightarrow$ that affected or was likely to affect neuromotor, mental, or sensory function. to such an extent that it greatly interfered with what is considered to be a $\overrightarrow{.}$ normal lifestyle. ${ }^{11}$ Denoting major disability entailed some degree of value $\vec{\sigma}_{\mathcal{O}}$ judgment. Data on individual children necessary to supplement informa- $\delta$ tion in this report are available on request.

Statistical analysis was carried out with the $\chi^{2}$ test with Yates's correction iv and Fisher's exact test where appropriate.

\section{Results}

Table I shows the number of infants and their mean birth weight at each week of gestation. There was no significant difference in the mean birth weights between this cohort and those obtained from the intrauterine $\infty$ growth chart based on a Melbourne population, ${ }^{12}$ which showed mean $Z$ birth weights at 24 to 28 weeks' gestation of 680 (SD 120) g, 784 (110) g, 835? (116) $\mathrm{g}, 1082$ (149) $\mathrm{g}$, and 1120 (217) g, respectively. The birthweight $\frac{\Phi}{3}$ distribution for each week of gestation showed minimal skew, and only five $\overline{0}$ infants had birth weights below the 10th percentile.

Major malformations found in 14 infants (4\%) were: congenital hydro- $\vec{\varphi}$ cephalus (two), tracheo-oesophageal atresia (two), trisomy 21 (two), multiple $\infty^{\circ}$ anomalies (two), trisomy 15 (one), triploidy $69 \mathrm{XXY}$ (one), anencephaly. (one), prosencephaly (one), exomphalos (one), and arthrogryposis (one). Table I shows that total survival at 1 year was $54 \%$ ( $95 \%$ confidence interval (CI) $49 \%$ to $59 \%$ ) and survival in those without major malformations (corrected survival) was $56 \%(51 \%$ to $61 \%)$.

Of the 192 long term survivors, 191 had standardised neurodevelopmental data available: 188 were from the Queen Victoria Medical Centre clinic and $\varrho$ three from follow up programmes interstate or overseas. The remaining $\overrightarrow{\overrightarrow{0}}$ survivor, who was of 28 weeks' gestation, went to Fiji and was lost to follow 3 up. Table I shows that the incidence of impairment was $19 \%$ (95\% CI $7 \%$ to $31 \%)$ and the incidence of disability $12 \%(7 \%$ to $17 \%)$. The 36 children? (19\%) with impairment had cerebral palsy (21 children (11\%)), developmental delay $(14(7 \%))$, blindness ( $\operatorname{six}(3 \%))$ and sensorineural deafness (five $(3 \%))$. Of the 21 children with cerebral palsy, 13 had hemiplegia, four had quadriplegia, two had diplegia, and two had monoplegia. Eight children had $\frac{}{3}$ two impairments each, and one had three impairments. There was no. significant difference in the incidence of impairment between the 23-25 week and $26-28$ week groups.

Twenty three children (12\%) were judged to have a major disability. Of 0 the 13 children whose single impairment did not greatly interfere with any function, nine had mild cerebral palsy, two had hearing loss that was $\sigma$ corrected with a hearing aid, and two had mild developmental delay. The $D$ child with three impairments and one of the children with two impairments had Haemophilus influenzae meningitis and adenovirus encephalitis at $7 \overline{\mathrm{N}}$ months and 15 months of age, respectively. Their impairments were not $\mathrm{N}$ considered to be of perinatal origin. A recalculation of the incidence of $\omega$ impairment, excluding these two children, gave an incidence of $18 \%$ (34 of 189 children).

Survival and the incidence of impairment in boys and girls were not $\frac{\text { त }}{\mathscr{D}}$ significantly different (tables II and III). The difference in survival between $\stackrel{\mathscr{C}}{?}$ boys and girls was $8 \%(95 \% \mathrm{CI}-3 \%$ to $19 \%)$. The difference in incidence of impairment was $11 \%$ (-22\% to $0 \%$ ). As survival was relatively lower and the $\overline{0}$ incidence of impairment was relatively higher in boys than in girls, the $\overrightarrow{\mathbb{D}}$ normal survival (the number of normal survivors expressed as a percentage $\underset{\mathbb{}}{\mathbb{}}$ of total livebirths) was significantly lower in boys than in girls (39\%v v1\%; $\cong$ $\mathrm{p}<0.05$ ).

Survival and impairment in 1977-80 and 1981-4 were not significantly $ᄋ$ different (tables II and III). The difference between survival in 1977-80 and 0 $1981-4$ was $4 \%(95 \% \mathrm{CI}-15 \%$ to $7 \%)$. The difference in the incidence of impairment between these years was also $4 \%(-15 \%$ to $7 \%)$. 
TABLE $\longmapsto$ Survival and neurodevelopmental outcome

\begin{tabular}{|c|c|c|c|c|c|c|c|}
\hline $\begin{array}{l}\text { Gestation } \\
\text { (weeks) }\end{array}$ & $\begin{array}{l}\text { No of } \\
\text { infants }\end{array}$ & $\begin{array}{c}\text { Mean (SD) } \\
\text { birth weight (g) }\end{array}$ & $\begin{array}{l}\text { No of infants with } \\
\text { malformation }\end{array}$ & $\begin{array}{c}\text { Total No (\%) of } \\
\text { survivors }\end{array}$ & $\begin{array}{l}\text { Corrected No (\%) } \\
\text { of survivors }\end{array}$ & $\begin{array}{c}\text { No }(\%) \text { of } \\
\text { survivors with } \\
\text { impairment }\end{array}$ & $\begin{array}{c}\text { No (\%) of } \\
\text { survivors with } \\
\text { major disability }\end{array}$ \\
\hline $\begin{array}{l}23 \\
24 \\
25 \\
26 \\
27 \\
28\end{array}$ & $\begin{array}{l}28 \\
40 \\
44 \\
62 \\
87 \\
95\end{array}$ & $\begin{array}{r}616(91) \\
691(99) \\
759(116) \\
929(181) \\
1033(171) \\
1112(220)\end{array}$ & $\begin{array}{l}1 \\
0 \\
1 \\
4 \\
4 \\
4\end{array}$ & $\begin{array}{l}2(7) \\
13(33) \\
11(25) \\
35(56) \\
63(72) \\
68(72)\end{array}$ & $\begin{array}{l}2(7) \\
13(33) \\
11(26) \\
35(60) \\
63(76) \\
68(75)\end{array}$ & $\begin{array}{r}1(50) \\
2(15) \\
5(45) \\
9(26) \\
9(14) \\
10(15)\end{array}$ & $\begin{array}{l}1(50) \\
1(8) \\
3(27) \\
7(20) \\
6(10) \\
5(7)\end{array}$ \\
\hline Total & 356 & $932(243)$ & 14 & $192(54)$ & $192(56)$ & $36(19)$ & $23(12)$ \\
\hline
\end{tabular}

TABLE II-Corrected survival in subgroups. Figures are number of survivors/number of livebirths (\% survival)

\begin{tabular}{|c|c|c|c|c|c|c|c|}
\hline \multirow[b]{2}{*}{ Subgroups } & \multicolumn{6}{|c|}{ Gestation (weeks) } & \multirow[b]{2}{*}{ Total } \\
\hline & 23 & 24 & 25 & 26 & 27 & 28 & \\
\hline $\begin{array}{l}\text { Boys } \\
\text { Girls }\end{array}$ & $\begin{array}{l}2 / 15(13) \\
0 / 12\end{array}$ & $\begin{array}{r}3 / 20(15) \\
10 / 20(50)\end{array}$ & $\begin{array}{l}2 / 16(13) \\
9 / 27(33)\end{array}$ & $\begin{array}{l}18 / 29(62) \\
17 / 29(59)\end{array}$ & $\begin{array}{l}35 / 48(73) \\
28 / 35(80)\end{array}$ & $\begin{array}{l}29 / 43(67) \\
39 / 48(81)\end{array}$ & $\begin{array}{r}89 / 171(52) \\
103 / 171(60)\end{array}$ \\
\hline $\begin{array}{l}1977-80 \\
1981-4\end{array}$ & $\begin{array}{l}0 / 8 \\
2 / 19(11)\end{array}$ & $\begin{array}{l}6 / 17(35) \\
7 / 23(30)\end{array}$ & $\begin{array}{l}5 / 18(28) \\
6 / 25(24)\end{array}$ & $\begin{array}{l}18 / 29(62) \\
17 / 29(59)\end{array}$ & $\begin{array}{l}29 / 39(74) \\
34 / 44(77)\end{array}$ & $\begin{array}{l}31 / 41(76) \\
37 / 50(74)\end{array}$ & $\begin{array}{r}89 / 152(59) \\
103 / 190(55)\end{array}$ \\
\hline $\begin{array}{l}\text { Singleton } \\
\text { Multiple }\end{array}$ & $\begin{array}{l}2 / 19(11) \\
0 / 8\end{array}$ & $\begin{array}{l}13 / 35(37) \\
0 / 5\end{array}$ & $\begin{array}{c}10 / 24(42) \\
1 / 19(5)\end{array}$ & $\begin{array}{c}33 / 54(61) \\
2 / 4(50)\end{array}$ & $\begin{array}{l}53 / 68(78) \\
10 / 15(67)\end{array}$ & $\begin{array}{l}57 / 76(75) \\
11 / 15(73)\end{array}$ & $\begin{array}{c}168 / 276(61) \\
24 / 66(36) \int_{\star}\end{array}$ \\
\hline
\end{tabular}

${ }^{\star} \mathrm{p}<0.01$.

TABLE III-Incidence of impairment in subgroups. Figures are number of babies with impairment/number of survivors (\% impaired)

\begin{tabular}{|c|c|c|c|c|c|c|c|}
\hline \multirow[b]{2}{*}{ Subgroups } & \multicolumn{6}{|c|}{ Gestation (weeks) } & \multirow[b]{2}{*}{ Total } \\
\hline & 23 & 24 & 25 & 26 & 27 & 28 & \\
\hline $\begin{array}{l}\text { Boys } \\
\text { Girls }\end{array}$ & $1 / 2(50)$ & $\begin{array}{l}0 ! 3 \\
2 / 10(20)\end{array}$ & $\begin{array}{ll}0 / 2 & \\
5 / 9 & (56)\end{array}$ & $\begin{array}{l}7 / 18(39) \\
2 / 17(12)\end{array}$ & $\begin{array}{l}8 / 35(23) \\
1 / 28 \quad(4)\end{array}$ & $\begin{array}{l}6 / 29(21) \\
4 / 38(11)\end{array}$ & $\begin{array}{l}22 / 89(25) \\
14 / 102(14)\end{array}$ \\
\hline $\begin{array}{l}1977-80 \\
1981-4\end{array}$ & $1 / 2(50)$ & $\begin{array}{l}\text { 1/ } 6(17) \\
1 / 7(14)\end{array}$ & $\begin{array}{lll}3 / 5 & (60) \\
2 / & 6 & (33)\end{array}$ & $\begin{array}{l}6 / 18(33) \\
3 / 17(18)\end{array}$ & $\begin{array}{l}4 / 29(14) \\
5 / 34(15)\end{array}$ & $\begin{array}{l}5 / 31(16) \\
5 / 36(14)\end{array}$ & $\begin{array}{l}19 / 89(21) \\
17 / 102(17)\end{array}$ \\
\hline $\begin{array}{l}\text { Singleton } \\
\text { Multiple }\end{array}$ & $1 / 2(50)$ & $2 / 13(15)$ & $\begin{array}{l}4 / 10(40) \\
1 / 1(100)\end{array}$ & $\begin{array}{l}8 / 33(24) \\
1 / 2(50)\end{array}$ & $\begin{array}{l}6 / 53(11) \\
3 / 10(30)\end{array}$ & $\begin{array}{l}6 / 56(11) \\
4 / 11(36)\end{array}$ & $\left.\begin{array}{r}27 / 167(16)\} \\
9 / 24(38)\end{array}\right\}$ \\
\hline
\end{tabular}

${ }^{\star} \mathrm{p}<0.01$.

TABLE IV-Outcome of single and multiple births for each week of gestation (corrected for malformation). Figures are numbers ( $\%$ ) of patients

\begin{tabular}{|c|c|c|c|c|c|c|}
\hline \multirow{2}{*}{$\begin{array}{l}\text { Gestation } \\
\text { (weeks) }\end{array}$} & \multicolumn{2}{|c|}{ Normal } & \multicolumn{2}{|c|}{ Impaired } & \multicolumn{2}{|c|}{ Dead } \\
\hline & Single & Multiple & Single & Multiple & Single & Multiple \\
\hline 23 & $1(5)$ & & $1(5)$ & & $17(90)$ & $8(100)$ \\
\hline 24 & $11(31)$ & & $2(6)$ & & $22(63)$ & $5(100)$ \\
\hline 25 & $6(25)$ & & $4(17)$ & $1(5)$ & $14(58)$ & $18(95)$ \\
\hline 26 & $25(46)$ & $1(25)$ & $8(15)$ & $1(25)$ & $21(39)$ & $2(50)$ \\
\hline 27 & $47(69)$ & $7(47)$ & $6(9)$ & $3(20)$ & $15(22)$ & $5(33)$ \\
\hline 28 & $51(67)$ & $7(46)$ & $6(8)$ & $4(27)$ & $19(25)$ & $4(27)$ \\
\hline
\end{tabular}

The 66 multiple births $(19 \%)$ had a lower survival $(p<0.001)$ and higher incidence of impairment $(p<0.01)$ than singleton births. The difference in survival between singleton and multiple births was $25 \%(95 \%$ CI $12 \%$ to $38 \%$ ). The difference between the incidence of impairment was $26 \%$ ( $24 \%$ to $28 \%$ ). Further analysis showed that the difference in survival between multiple and singleton births in the 26-28 week group was not significant $(68 \% v 72 \%)$, while that in the $23-25$ week group remained significant $(3 \% v$ $32 \% ; \mathrm{p}<0.005)$. The difference in incidence of impairment between multiple and singleton births in the 26-28 week group was significant $(39 \% v$ $14 \% ; p<0.01$ ), but it was not possible to comment on the difference in the 23-25 week group because only one infant in the multiple birth group survived. Table IV summarises the outcome of singleton and multiple births for each week of gestation.

Of the 108 singleton infants who died, $80(74 \%)$ did so in the early neonatal period (of whom $25(23 \%)$ died within one hour after birth, $36(33 \%)$ between one and 24 hours, and $19(18 \%)$ between two and seven days), 15 $(14 \%)$ in the late neonatal period, and $13(12 \%)$ in the postneonatal period (of whom three died in infancy after discharge). Table $\mathrm{V}(a)$ gives the worst potential outcome for singleton infants, based on prediction before delivery, as well as the better potential outcome predicted after resuscitation (table $\mathrm{V}$ (b)) once major malformation had been excluded and the infant had survived the critical first hour. By the end of the first week after birth, when most of the deaths had occurred, the third set of predictions of outcome (table $\mathrm{V}(c)$ ) became relevant in counselling parents on the infant's potential outcome.

TABLE V-Predictions of outcome before birth, after resuscitation, and at 1 week for singleton births

\begin{tabular}{|c|c|c|c|c|}
\hline \multirow[b]{2}{*}{$\begin{array}{l}\text { Gestation } \\
\text { (weeks) }\end{array}$} & \multicolumn{4}{|c|}{ Predicted outcome (\% of births) } \\
\hline & Normal & $\begin{array}{c}\text { Major } \\
\text { disability }\end{array}$ & $\begin{array}{c}\text { Other } \\
\text { impairments }\end{array}$ & Dead \\
\hline \multicolumn{5}{|c|}{ (a) Before birth } \\
\hline $\begin{array}{l}23 \\
24 \\
25 \\
26 \\
27 \\
28\end{array}$ & $\begin{array}{r}5 \\
31 \\
24 \\
44 \\
68 \\
64\end{array}$ & $\begin{array}{l}5 \\
3 \\
8 \\
9 \\
4 \\
5\end{array}$ & $\begin{array}{l}3 \\
8 \\
5 \\
3 \\
2\end{array}$ & $\begin{array}{l}90 \\
63 \\
60 \\
42 \\
25 \\
29\end{array}$ \\
\hline \multicolumn{5}{|c|}{ (b) After resuscitation } \\
\hline $\begin{array}{l}23 \\
24 \\
25 \\
26 \\
27 \\
28\end{array}$ & $\begin{array}{l}20 \\
46 \\
30 \\
53 \\
73 \\
71\end{array}$ & $\begin{array}{r}20 \\
4 \\
10 \\
11 \\
5 \\
6\end{array}$ & $\begin{array}{r}4 \\
10 \\
6 \\
2 \\
2\end{array}$ & $\begin{array}{l}60 \\
46 \\
50 \\
30 \\
20 \\
21\end{array}$ \\
\hline \multicolumn{5}{|c|}{ (c) At 1 week } \\
\hline $\begin{array}{l}23 \\
24 \\
25 \\
26 \\
27 \\
28\end{array}$ & $\begin{array}{l}33 \\
69 \\
46 \\
63 \\
86 \\
78\end{array}$ & $\begin{array}{r}33 \\
6 \\
15 \\
13 \\
5 \\
6\end{array}$ & $\begin{array}{r}6 \\
16 \\
7 \\
4 \\
3\end{array}$ & $\begin{array}{r}33 \\
19 \\
23 \\
17 \\
5 \\
13\end{array}$ \\
\hline
\end{tabular}


TABLE VI-Uncorrected hospital survival and neurodevelopmental outcome of extremely preterm infants. Figures are number of survivors/number of livebirths (\% survival)

\begin{tabular}{|c|c|c|c|c|c|c|c|c|c|}
\hline \multirow{2}{*}{$\begin{array}{l}\text { Reference } \\
\text { study }\end{array}$} & \multirow{2}{*}{$\begin{array}{l}\text { Year of birth of } \\
\text { cohort }\end{array}$} & \multicolumn{6}{|c|}{ Gestation (weeks) } & \multirow{2}{*}{$\begin{array}{l}\text { No of survivors } \\
\text { followed up }\end{array}$} & \multirow{2}{*}{$\begin{array}{l}\text { No }(\%) \text { of } \\
\text { survivors witt } \\
\text { impairment }\end{array}$} \\
\hline & & 23 & 24 & 25 & 26 & 27 & 28 & & \\
\hline Milligan et $a l^{1}$ & $1979-82$ & 1/ $7(14)$ & $9 / 23(39)$ & $28 / 44(64)$ & $34 / 45(76)$ & $45 / 60(75)$ & $71 / 88(81)$ & 158 & $33(21)$ \\
\hline Kitchen et $\mathrm{l}^{3}$ & $1977-82$ & & $2 / 27(7)$ & $11 / 54(20)$ & $36 / 80(45)$ & $47 / 67(70)$ & $76 / 98(78)$ & 111 & $15(14)$ \\
\hline Present study & 1977.84 & $2 / 28 \quad(7)$ & $13 / 40(33)$ & $11 / 44(25)$ & $36 / 62(58)$ & $63 / 87(72)$ & $70 / 95(74)$ & 191 & $36(19)$ \\
\hline
\end{tabular}

\section{Discussion}

Several published studies have reported on the outcome of infants whose birth weights were below $750 \mathrm{~g}$ or $800 \mathrm{~g} .{ }^{13.17}$ The study cohorts, however, contained $46 \%$ to $100 \%$ of outborn infants, ${ }^{13-16}$ and $32 \%$ to $34 \%$ were small for gestational age. ${ }^{13}{ }^{17}$ Referral for treatment of extremely low birthweight livebirths born outside perinatal centres results in a great selection bias. The lack of a denominator for outborn livebirths makes the incidence of survival reported for other cohorts meaningless. In the state of Victoria, Australia, we have reported that only $48 \%$ of extremely low birthweight infants born outside perinatal centres were referred for neonatal intensive care, and all those not transported died.' Furthermore, the incidence of major disability in outborn survivors was over three times that of inborn survivors. ${ }^{18}$ In cohorts selected for weight infants who are small for gestational age are expected to be more mature than those whose weight is the same but is appropriate for their age. Hence the mortality of infants with appropriate weights was about three times higher than that of the infants whose growth was retarded. ${ }^{10}$ To obtain an accurate prognosis for extremely preterm infants outcome according to gestation has to be reported in an exclusively inborn population in which infants who are small for gestational age are not over-represented.

Published data on survival and neurodevelopmental outcome based on gestation at birth are sparse. Two earlier studies reported neonatal mortality by week of gestation but did not have follow up data. ${ }^{19}{ }^{20}$ Many of these small infants die after the statutory period of 28 days, often from complications that are direct consequences of extreme prematurity. ${ }^{21}$ It is therefore necessary to report infant mortality that includes postneonatal deaths either in hospital or after discharge home. Two perinatal centres besides ours have published data on survival and neurodevelopmental outcome by week of gestation in large inborn cohorts of extremely preterm infants (table VI). The relatively low survival of children born at 24 to 26 weeks' gestation in one institution was probably a result of its selective treatment policy in the neonatal intensive care unit, as 41 infants (12\% of the study population or $27 \%$ of deaths) died after admission when ventilator care was not offered because of extreme prematurity. $^{3}$

Two previous studies, which contained $62 \%^{22}$ and $100 \%^{23}$ outborn infants, reported no differences in survival between boys and girls of extremely low birth weight, while another study reported a significantly lower normal survival in boys in an inborn population. ${ }^{10}$ Male sex was one of the adverse factors associated with death as well as impairment in a study that compared 39 infants who died in the neonatal period and 34 infants with impairment with matched normal control infants, all of whom were inborn at 26-30 weeks' gestation. ${ }^{24}$ The finding that boys have slower lung maturation compared with girls of similar gestation probably explains their higher mortality. ${ }^{25}$

Multiple births have been associated with increased mortality in an extremely preterm population ${ }^{3}$ as well as in an extremely low birthweight population. ${ }^{10}$ This study confirmed that multiple births have a higher risk of death as well as impairment. The increased perinatal mortality associated with multiple births is well documented in other reports. ${ }^{26}{ }^{27}$ Some studies have suggested there is an advantage in caesarean delivery for preterm twins. ${ }^{28}{ }^{29} \mathrm{~A}$ study that included more mature infants, however, showed no evidence that caesarean section reduced perinatal asphyxia, trauma, or perinatal mortality in multiple births. ${ }^{30}$

Table $\mathrm{V}$ was constructed to aid the development of guidelines on when perinatal intensive care is justified, whether obstetric inter- vention for fetal reasons is warranted, and what initial and $\frac{\stackrel{5}{0}}{0}$ ongoing prognoses to give to parents. The predictions made before $\frac{}{0}$ delivery (table $\mathrm{V}(a)$ ) are useful in perinatal consultation between $\overline{\bar{N}}$ obstetricians and neonatologists on the appropriate management of $\overparen{\nabla}$ extremely preterm labour. They may also give parents with threatened preterm labour an opportunity to discuss electively and $\stackrel{s}{ }$ in an informed manner treatment choices for their infant of $\overrightarrow{0}$ borderline viability should extremely preterm birth occur. The $\overrightarrow{\vec{\omega}}$ predictions made after resuscitation (table $\mathrm{V}(b)$ ) are useful to the $\vec{\omega}$ neonatologist when he or she meets with the parents immediately $\frac{}{5}$ after the infant has stabilised in the neonatal intensive care unit. The 3 prognosis at this stage is improved by excluding major malforma- iv tions and the continued survival of the infant after resuscitation. $\omega$ Because three quarters of those who died had done so by 1 week of age a revised prognosis was necessary after the early neonatal period $\%$ (table $\mathrm{V}(c)$ ). As the risk period for the development and extension of $\vec{N}$ periventricular haemorrhage is also the first week after birth the 8 infant's prognosis can be further refined if cerebral ultrasound 0 findings, based on the documented effect of periventricular haemor- $\infty$ rhage on neurodevelopmental outcome, are known..$^{31}{ }^{32}$ As ultra- $z$ sonographic diagnosis of periventricular leucomalacia cannot be made with certainty until three to seven weeks after birth, ${ }^{33} \frac{\mathrm{D}}{3}$ however, optimism about normal neurodevelopmental outcome is unwarranted within the neonatal period.

In this study data on survival and neurodevelopmental outcome $\vec{\varphi}$ have been reported, specific high risk subgroups identified, and $\stackrel{\circ}{\circ}$ outcome predicted for infants born at 23 to 28 weeks' gestation, many of whom were previously considered non-viable. Decisions to resuscitate and provide life support treatment for these infants currently depend on the personal attitudes and philosophy of the perinatal doctors, with variable input from parents. We have $\mathbb{\Phi}$ referred only to neurodevelopmental outcome ascertained up to $2 \stackrel{\varrho}{\Rightarrow}$ years of age. To accurately diagnose impairments that result in $\frac{0}{3}$ lesser disability a longer follow up period of six to eight years is $\frac{3}{5}$ required. Furthermore, this population of survivors represents a high risk group with specific problems of growth, lung disease, gastrointestinal conditions, and behavioural disorders. ${ }^{3+37}$ When weighing the final outcome, therefore, the ongoing medical, financial, and social costs must not be ignored. The impending availability of surfactant replacement therapy ${ }^{38}$ and high frequency ventilation $^{39}$ show promise in improving survival and neuro- $\delta$ developmental outcome for such extremely preterm infants. The poor reproductive history of these mothers, ${ }^{40}$ and their unfavour- $\frac{\rho}{9}$ able subsequent obstetric experience, ${ }^{41}$ emphasise the importance of $N$ research towards preventing or treating the cause of extreme $\rightarrow$ prematurity. In the mean time continued efforts are required to monitor the application of intensive care to progressively smaller and more immature infants. Each perinatal centre providing this $\mathrm{N}$ type of care should develop in an ongoing fashion its own outcome $\omega$ predictions for use in its own decision making process.

\section{References}

1 Milligan JE, Shennan AT, Hoskins EM. Perinatal intensive care: where and how to draw the line.

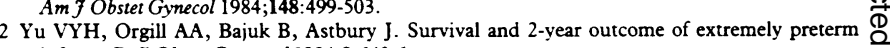

infants. Br $\mathcal{F}$ Obstet Gynaecol 1984;9:640-6.
3 Kitchen W, Ford GW, Dovle LW, et al. Caesarean section or vaginal delivery at 24 to 28 weeks' gestation: comparison of survival and neonatal and two-year morbidity. Obstet Gynecol $?$ 1985;66:149-57.
.

4 Chervenak FA, Berkowitz GS, Thorton J, et al. A comparison of sonographic estimation of fetal very low-birth weight fetus. Am J Obstet Gynecol 1985;152:47-50. 
5 Kitchen WH, Campbell NT, Drew JH, Murton LJ, Roy RND, Yu VYH. Provision of perinata services and survival of extremely low birthweight infants in Victoria. Med f Aust 1983;2:314-8.

6 World Health Organisation. Recommended definitions, terminology and format for statistical table related to the perinatal period and use of a new certificate for cause of perinatal deaths. Acta Obstet Gynecol Scand 1977;56:247-53.

7 Spinnato, Sibai BM, Shaver DC, Anderson GD. Inaccuracy of Dubowitz gestational age in low birth weight infants. Obstet Gynecol 1984;63:491-5.

8 Kitchen WH, Yu VYH, Orgill AA, et al. Collaborative study of very low birthweight infants: outcome of two year old survivors. Lancet 1982;i:1457-61.

9 Orgill AA, Astbury J, Bajuk B, Yu VYH. Early development of infants $1000 \mathrm{~g}$ or less at birth. Arch Dis Child 1982;57:823-7.

10 Yu VYH, Wong PY, Bajuk B, Orgill AA, Astbury J. Outcome of extremely low birthweight infants. Br J Obstet Gynaecol 1986;93:162-70.

11 Stewart AL, Turcan DM, Rawlings G, Reynolds EOR. Prognosis for infants weighing $1000 \mathrm{~g}$ or less at birth. Arch Dis Child 1977;52:97-104.

12 Kitchen WH, Bajuk B, Lissenden JV, Yu VYH. Intrauterine growth charts from 24 to 29 weeks' gestation. Aust Paediatr 7 1981;17:269-72.

13 Britton SB, Fritzhardinge PM, Ashby S. Is intensive care justified for infants weighing less than $801 \mathrm{~g}$ at birth? I Pediatr 1981;99:937-43.

14 Bennett FC, Robinson NM, Sells CJ. Growth and development of infants weighing less than 800 grams at birth. Pediatrics 1983;71:319-23.

15 Hirata T, Epcar JT, Walsh A, et al. Survival and outcome of infants 501 to $750 \mathrm{gm}$ : a six yea experience. $\mathcal{F}$ Pediatr 1983;102:741-8.

16 Buckwald S, Zorn WA, Egan EA. Mortality and follow-up data for neonates weighing $500-800 \mathrm{~g}$ at birth. Am F Dis Child 1984;138:779-82.

17 Hack M, Fanaroff AA. Changes in the delivery room care of the extremely small infant $(<750 \mathrm{~g})$. Effects on morbidity and outcome. $N$ Engl $7 \mathrm{Med} 1986 ; 314: 660$-t.

18 Kitchen W, Ford G, Orgill AA, et al. Outcome of infants of birthweight $500-599 \mathrm{~g}$ : a regional study of 1979-1980 births. $\mathcal{F}$ Pediatr 1984;104:921-7.

19 Dillon WP, Egan EA. Aggressive obstetric management in late second-trimester deliveries. Obstet Gynecol 1981;58:685-90.

20 Herschel M, Kennedy JL, Jr, Kayne HL, Henry M, Cetrulo CL. Survival of infants born at 24 to 28 weeks' gestation. Obstet Gynecol 1982;60:154-8.

21 Yu VYH, Watkins A, Bajuk B. Neonatal and postneonatal mortality in very low birthweight infants. Arch Dis Child 1984;59:987-99.

22 Bhat R, Raju TNK, Vidyasagar D. Immediate and long-term outcome of infants less than 1000 grams. Crit Care Med 1978;6:147-50

23 Pape KE, Buncic RJ, Ashby S, Fitzhardinge PM. The status at two years of low birthweigh infants born in 1974 with birthweights of less than $1001 \mathrm{~g}$. F Pediatr 1978;92:253-60.

24 Shennan AT, Milligan JE, Hoskins EM. Perinatal factors associated with death or handicap in very preterm infants. Am $\mathcal{F}$ Obstet Gynecol 1985;151:231-8.
25 Khoury MJ, Marks JS, McCarthy BJ, Zaro SM. Factors affecting the sex differential in neonatal mortality: the role of respiratory distress syndrome. Am f Obstet Gynecol 1985;151:777-82. 26 McCarthy BJ, Sachs BP, Layde PM, Burton A, Terry JS, Rochat R. The epidemiology of neonatal deaths in twins. Am $\mathcal{F}$ Obstet Gynecol 1981;141:252-6.

27 Hawrylyshyn PA, Barkin M, Bernstein A, Papsin FR. Twin pregnancies-a continuing perinatal challenge. Obstet Gynecol 1982;59:463-6.

28 Barrett JM, Staggs SM, Van Hooydonk JE, Growdon JH, Killam AP, Boem FH. The effect of delivery upon neonatal outcome in premature twins. Am 7 Obstet Gynecol 1982;143:360-4.

29 Chervenak FA, Johnson RE, Berkowitz RL, Grannum P, Hobbins JC. Is routine cesarean section necessary for vertex-breech and vertex-transverse twin gestations? Am $\mathcal{f}$ Obstet Gynecol 1984;148: 1-5.

30 Bell D, Johnansson D, McLean FH, Usher RH. Birth asphyxia, trauma, and mortality in twins: has cesarean section improved outcome? Am $\mathcal{F}$ Obstet Gynecol 1986;154:235-9.

31 Yu VYH, Downe L, Astbury J, Orgill AA, Bajuk B. Perinatal factors associated with adverse outcome in extremely low birthweight infants. Arch Dis Child 1986;61:554-8.

32 Szymonowicz W, Yu VYH, Bajuk B, Astbury J. Neurodevelopmental outcome of periventricular haemorrhage and leukomalacia in infants 1250 grams or less at birth. Early Hum Dev 1986;14: haem.

33 Szymonowicz W, Yu VYH. Periventricular haemorrhage and leukomalacia in extremely low birthweight infants. Aust Paediatr F 1986;22:207-10

34 Yu VYH, Orgill AA, Lim SB, Bajuk B. Astbury J. Growth and development of very low birthweight children recovering from bronchopulmonary dysplasia. Arch Dis Child 1983;58 791-4.

35 Morgan MEI. Late morbidity of very low birthweight infants. Br Med f 1985;291:171-3.

36 Astbury J, Orgill AA, Bajuk B, Yu VYH. Neonatal and neurodevelopmental significance of behaviour in very low birthweight children. Early Hum Dev 1985;11:113-21.

37 Astbury J, Orgill AA, Bajuk B, Yu VYH. The physical and neurobehavioural sequelae of growth failure in appropriate for gestational age very low birthweight children. Dev Med Child Neurol (in press).

38 Enhorning G, Shennan A, Possmayer F, Dunn M, Chen CP, Milligan J. Prevention of neonatal repiratory distress syndrome by tracheal instillation of surfactant: a randomised clinical trial. Pediatrics 1986;76:145-53.

39 Boynton BR, Mannino FL, Davis RF, Kopotic RJ, Friederichsen G. Combined high-frequency oscillatory ventilation in critically ill neonates. F Pediatr 1984;105:297-302.

40 Yu VYH, Bajuk B, Orgill AA, Astbury J. Viability of infants born at 24 to 26 weeks' gestation. Ann Acad Med 1985;14:563-71.

41 Yu VYH, Davis NG, Mercado M, Bajuk B, Astbury J. Subsequent pregnancy following the birth of an extremely low birthweight infant. Aust NZ F Obstet Gynaecol 1986;26:115-9.

(Accepted 14 August 1986)

\title{
Hip fractures in healthy patients: operative delay versus prognosis
}

\author{
R N VILLAR, S M ALLEN, S J BARNES
}

\begin{abstract}
One hundred and forty five women who had undergone hemiarthroplasty for a subcapital fracture of the femoral neck but who were otherwise fit were studied to determine whether undue delay between injury and operation influenced their social circumstances three months after surgery. The median delay for those patients who showed good rehabilitation at three months was 29 hours, but for those who showed poor rehabilitation it was 57 hours. This difference was significant.

It is suggested that a subcapital fracture in an otherwise fit elderly patient should therefore be regarded as a surgical emergency.
\end{abstract}

\section{Introduction}

It is widely accepted that elderly women with hip fractures undergo surgery on the next available operating list, frequently 24 hours or

\footnotetext{
Department of Orthopaedic Surgery, Southampton General Hospital, Southampton, Hants

R N VILLAR, BSC, FRCS, orthopaedic registrar

S M ALLEN, MB, BS, orthopaedic senior house officer

S J BARNES, BM, orthopaedic senior house officer

Correspondence to: $\mathrm{Mr} \mathbf{R} \mathrm{N}$ Villar, Department of Orthopaedic Surgery, Addenbrooke's Hospital, Cambridge CB2 2QQ.
}

more after admission. We present a retrospective study relating this operative delay to the social circumstances of the patient three months after surgery.

\section{Patients, methods, and results}

We studied 205 consecutive women patients, who had been admitted over 18 months and had undergone hemiarthroplasty for a displaced subcapital fracture of the femoral neck. Of the 205 patients, 60 had intercurrent illness that was likely to interfere with postoperative rehabilitation and were excluded from the study.

The social circumstances of each patient were assessed on admission and three months after surgery as $(a)$ independent if she lived without help from others; $(b)$ sheltered if she received substantial help with daily activities; or (c) resident in hospital if she lived in an institution. ${ }^{1}$ The time delay between injury and operation and typical reasons for delay were also recorded. At the review three months after surgery each patient was placed in one of two groups based on her social circumstances at that time. Group A consisted of patients whose circumstances were similar to those on admission, and group $\mathrm{B}$ consisted of patients whose circumstances had deteriorated and those who had died.

Statistical analysis was by Student's $t$ test. Results for operative delay produced a skewed distribution and $\log _{e}$ (operative delay) was therefore used to correct the findings.

Of the 145 patients, $98(68 \%)$ were admitted from an independent environment, $41(28 \%)$ were sheltered, and $6(4 \%)$ were resident in hospital. After three months similar percentages of each social category could be placed in group A $(81 \%$ independent, $78 \%$ sheltered, and $83 \%$ resident in hospital). No patient improved after surgery; a patient stayed the same, became worse, or died.

Patients in group A had a median delay of 29 (range 6-184 h; mean $31 \cdot 7 \mathrm{~h}$ ) and group B patients a median delay of 57 (range $24-528 \mathrm{~h}$; mean $74 \cdot 7 \mathrm{~h}$ ). 